\title{
Global experience of orthopaedic trauma surgeons facing COVID-19: a survey highlighting the global orthopaedic response
}

\author{
Bradley A. Lezak ${ }^{1} \cdot$ Peter A. Cole Jr ${ }^{2} \cdot$ Lisa K. Schroder ${ }^{3,4} \cdot$ Peter A. Cole ${ }^{3,4,5}$ (I)
}

Received: 15 May 2020 / Accepted: 18 May 2020 / Published online: 13 June 2020

(C) SICOT aisbl 2020

\begin{abstract}
Background The COVID-19 (SARS-CoV-2) pandemic has significantly affected all aspects of healthcare, including orthopaedics. Due to the unique challenges presented by COVID-19 as well as the distinct timeframes that it will surge in different geographies, much can be learned from the experiences of orthopaedic professionals in many global settings. The goal of this project is to characterize the preparations, strategies, lessons, and personal experiences of orthopaedic trauma surgeons and departments across the world in combating COVID-19. In doing so, we will shed light on current practices and challenges, which may help us manage the current pandemic in addition to preparing for future global pandemics that may arise.

Methods A 20-item questionnaire was sent out to 150 orthopaedic trauma surgeons representing 42 countries who were identified based on professional relationships and/or prior involvement in international meetings either led or participated by the senior author. Results The questionnaire was completed by 63 orthopaedic trauma surgeons representing 28 countries and 14 US states. The results of this study show that orthopaedic trauma departments across the world have been greatly impacted by COVID-19 with $91 \%$ of participating hospitals currently having a reduced case load compared with pre-COVID-19 and only $17 \%$ of respondents currently performing elective orthopaedic surgery. Furthermore, $30 \%$ of orthopaedic departments have deployed orthopaedic personnel to non-orthopaedic floors in order to help mitigate the increased patient load and $86 \%$ of respondents noted at least some shortage of PPE. Lastly $73 \%$ of participating orthopedic departments including those in LMICs, have incorporated telemedicine into their practice with a majority stating that it would most likely become a permanent change to their practice post-COVID- 19 .

Conclusion To our knowledge, this is the largest data set characterizing global COVID-19 situations and responses of orthopaedic trauma practices around the world. There is much to be learned from each of the participants' responses in order to persevere during the current pandemic, as well as to prepare for future pandemics as it relates specifically to orthopaedic trauma practices.
\end{abstract}

Keywords Coronavirus · COVID-19 $\cdot$ Orthopaedic trauma $\cdot$ Global Health $\cdot$ Global surgery $\cdot$ Telemedicine $\cdot$ Personal protective equipment (PPE)

Peter A. Cole

peter.a.cole@healthpartners.com

1 Miller School of Medicine, University of Miami, Miami, FL, USA

2 Miami Herbert Business School, Coral Gables, FL, USA

3 Department of Orthopaedic Surgery, Regions Hospital, University of Minnesota, 640 Jackson Street, St. Paul, MN 55101, USA

4 Department of Orthopaedic Surgery, University of Minnesota, Minneapolis, MN, USA

5 HealthPartners Orthopaedics \& Sports Medicine, Bloomington, MN, USA

\section{Introduction}

In early December 2019, a novel strain of coronavirus now known as coronavirus SARS (severe acute respiratory syndrome)-CoV-2, or COVID-19, broke out in Wuhan, China. The virus began to disseminate throughout the world, and on March 11, 2020, the World Health Organization (WHO) Director declared the 2019-nCoV outbreak a global pandemic, which classifies the outbreak as an international emergency $[1,2]$.

COVID-19 has severely altered the day-to-day life and operations for people, economies, and healthcare systems alike. The rapid spread of COVID-19 has created an expeditious implementation of new practices and principles that healthcare leaders have adopted in order to most effectively remain ahead of the curve. Unlike ever before, COVID-19 has 
highlighted geographical differences from provider to provider as to which methodologies were developed, how they were employed, and with what efficacy. In large part, these methodologies have been predicated upon characteristics specific to the host environment, such as viral seroprevalence, population density, socioeconomic factors, local governance, and resource limitations. For example, Milan, Italy, representative of a high population density and an overwhelming case load of COVID-19 positive patients, faces challenges distinct from those of Makwasa, Malawi, with lower population density and relatively low incidence of COVID-19.

Because the peak of COVID-19 cases have and will surge at different time points in different geographies, much can be learned about how various global providers have responded to the crisis [2-5]. Currently, there is a growing emphasis on the relevance of observational research in identifying factors, challenges, and responses to this pandemic among orthopaedic practices throughout the world [6-10]. Our team believes that there is value in learning from the experiences of orthopaedic professionals in many global settings, such that localized planning may transition from rapid-fire response to informed expectations and processes. Not only will these lessons allow us to better understand and overcome the current COVID-19 pandemic, but they will help the global orthopaedic community prepare for future outbreaks that may reach a scale such as the one we are living through today.

The goal of this project is to summarize the preparation, actions, lessons, and personal experiences of orthopaedic trauma surgeons and departments across the world in combating COVID-19. In doing so, we will shed light on current practices and challenges, which may help us manage the current pandemic in addition to preparing for future global pandemics that may arise.

\section{Methods}

\section{Study population}

Survey participation was carried out in the month of April 2020 between April 16, 2020, and April 20, 2020. Participation in this cross-sectional questionnaire was voluntary, and orthopaedic trauma surgeons were included in the study based on voluntary interest.

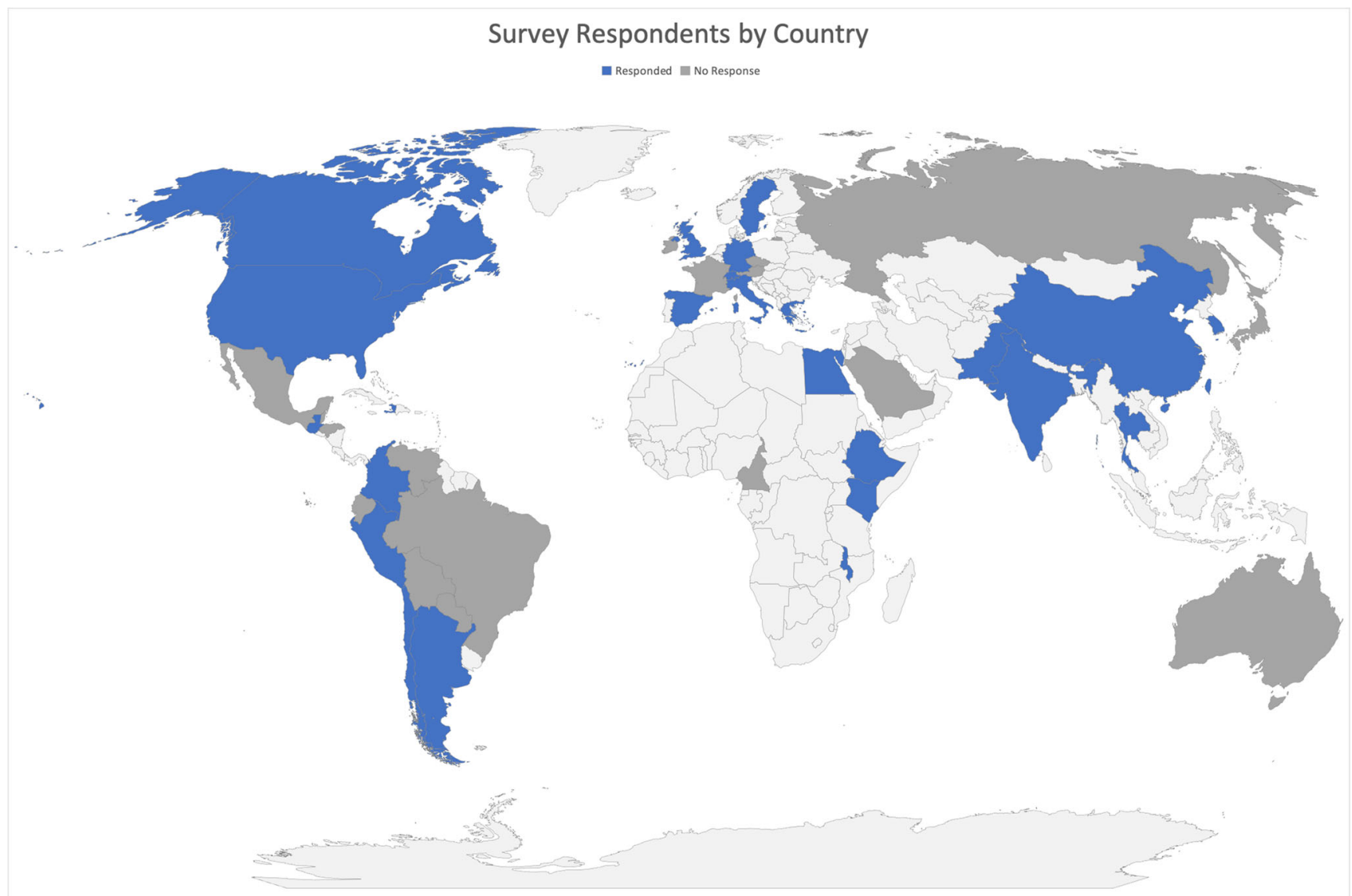

Fig. 1 Countries Represented by Survey Participants. Blue indicates a participating country. Dark Grey indicates a country where a questionnaire was sent, but no response was received 
Table 1 Participants orthopedic trauma practice location, hospital size, and number of surgeons

\begin{tabular}{|c|c|c|c|c|}
\hline Country & Hospital & Hospital size (\# of beds) & Urban/rural & \# of Orthopedic surgeons \\
\hline Argentina & Hospital Italiano de Buenos Aires & 750 & Urban & 60 \\
\hline Argentina & Ramos Mejia Hospital & 150 & Urban & 16 \\
\hline Canada & QE II Health Sciences Centre & 1100 & Urban & 15 \\
\hline Canada & Sunnybrook Health Sciences Centre & 1325 & Urban & 23 \\
\hline Canada & Foothills Medical Center & 1200 & Urban & 19 \\
\hline Colombia & Foundation Santa Fe de Bogota & 205 & Urban & 30 \\
\hline Chile & Las Condes Clinic & 253 & Urban & 42 \\
\hline Chile & Hospital Militar de Santiago & 357 & Urban & 28 \\
\hline China & Nanfang Hospital & 2500 & Urban & 50 \\
\hline Colombia & Instituto Colombiano del Dolor & 371 & Urban & 25 \\
\hline Colombia & IPS Universitaria Sede Clínica León XII & 618 & Urban & 25 \\
\hline Egypt & Assiut University Hospital & 358 & Urban & 85 \\
\hline Ethiopia & Black Lion (Tikur Anbessa) Hospital & 800 & Urban & 11 \\
\hline Ethiopia & Soddo Christian Hospital & 133 & Rural & 2 \\
\hline Gabon & Bongolo Hospital & 158 & Rural & 3 \\
\hline Germany & University of Freiburg Hospital & 1600 & Urban & 51 \\
\hline Greece & Iatriko Kentro & 383 & Urban & 10 \\
\hline Guatemala & El Pilar Hospital & 140 & Urban & 20 \\
\hline Haiti & HUP La Paix University Hospital & 300 & Rural & 6 \\
\hline Hong Kong & Queen Mary Hospital & 1706 & Urban & 55 \\
\hline Hong Kong & Tseung Kwan O Hospital & 667 & Urban & 22 \\
\hline India & Ganga Hospital Coimbatore & 486 & Urban & 107 \\
\hline Italy & Humanitas Research Institute & 162 & Urban & 60 \\
\hline Italy & Azienda Ospedaliera Universitaria Policlinico & 600 & Urban & 14 \\
\hline Italy & Vito Fazzi Lecce & 800 & Urban & 13 \\
\hline Kenya & Tenwek Hospital & 361 & Rural & 2 \\
\hline Malawi & Malamulo Adventist Hospital & 275 & Rural & 4 \\
\hline New Zealand & Waikato District Health Board & 600 & Urban & 18 \\
\hline Pakistan & Aga Khan University Hospital & 560 & Urban & 11 \\
\hline Peru & Amazonico Hospital & 120 & Rural & 3 \\
\hline Singapore & Tan Tock Seng Hospital & 1600 & Urban & 25 \\
\hline South Korea & Kyungpook National University Hospital & 951 & Urban & 35 \\
\hline South Korea & Korea University Guro Hospital & 1050 & Urban & 16 \\
\hline Spain & Vithas Hospital & 100 & Urban & 17 \\
\hline Sweden & Sahlgrenska University Hospital & 2000 & Urban & 80 \\
\hline Sweden & Linköping University Hospital & 600 & Urban & 27 \\
\hline Switzerland & Unispital Zurich & 980 & Urban & 16 \\
\hline Switzerland & Luzerner Kantonsspital & 900 & Urban & 14 \\
\hline Switzerland & University Hospital Basel & 670 & Urban & 25 \\
\hline Switzerland & Kantonsspital Graubünden Hospital & 770 & Urban & 15 \\
\hline Taiwan & Taipei Veterans General Hospital, Taiwan & 3100 & Urban & 25 \\
\hline Thailand & Chiang Mai University Hospital & 1400 & Urban & 20 \\
\hline Thailand & Bangkok International Hospital & 580 & Urban & 25 \\
\hline UK & Leeds General Infirmary University Hospital & 1103 & Urban & 40 \\
\hline UK & University College London hospital & 665 & Urban & 14 \\
\hline USA & University of Missouri - Columbia SOM & 247 & Urban & 35 \\
\hline USA & Central Vermont hospital & 122 & Rural & 4 \\
\hline USA & Johns Hopkins Hospital & 1154 & Urban & 15 \\
\hline USA & Sanford Bemidji & 196 & Rural & 4 \\
\hline
\end{tabular}


Table 1 (continued)

\begin{tabular}{|c|c|c|c|c|}
\hline Country & Hospital & Hospital size (\# of beds) & Urban/rural & \# of Orthopedic surgeons \\
\hline USA & Providence St Peter's Hospital & 390 & Urban & 15 \\
\hline USA & Oregon Health \& Science University & 556 & Urban & 16 \\
\hline USA & Erie County Medical Center & 906 & Urban & 20 \\
\hline USA & LAC + USC Medical Center & 600 & Urban & 13 \\
\hline USA & St. Mary's Medical Center Hospital & 281 & Rural & 7 \\
\hline USA & Memorial Hospital of Sweetwater County & 58 & Rural & 3 \\
\hline USA & University of New Mexico & 618 & Urban & 25 \\
\hline USA & Ohio State University & 1113 & Urban & 33 \\
\hline USA & Mayo Clinic Health System Eau Claire & 193 & Rural & 9 \\
\hline USA & Stormont Vail Hospital & 586 & Rural & 10 \\
\hline
\end{tabular}

\section{Data acquisition}

In order to describe the trend of total cases and total deaths due to COVID-19, the Johns Hopkins University Coronavirus COVID-19 Global Cases by the Center for Systems Science and Engineering (CSSE) and the Institute for Health Metrics and Evaluation (IHME) databases were referenced [11, 12]. Several time points were included throughout this five month span in order to understand the evolution of the case load and death rate.

\section{Questionnaire}

A 20-item questionnaire was sent out to 150 orthopaedic trauma surgeons representing 42 countries across the globe who were identified based on professional relationships and/or prior involvement in international meetings either led or participated by the senior author. Each participant was first asked to identify personal demographics including city, country, and hospital of their orthopaedic practice. Participants were then asked a series of specific questions related to their orthopaedic practice in order to understand the setting (urban vs. rural), volume of orthopaedic cases pre- and during COVID-19, and types of procedures currently being performed during COVID-19.

Participants were then asked to delineate how COVID-19 has affected their orthopaedic practice in terms of number of orthopedic consultations per day, number of orthopaedic cases treated pre- and during COVID-19, as well as how the current orthopedic injuries presenting during COVID-19 compared with injury presentations prior to the outbreak.

Next, participants were asked to describe their adoption of telemedicine practices. Each participant differentiated between the adoption of telephone-only visits, telephone and video visits, or no adoption of telemedicine visits at all. Furthermore, participants were asked to describe how they believed the rapid changes in medicine that are occurring due to the COVID-19 pandemic would permanently affect their future practices after the global pandemic ends.

Each participant was then asked several questions with regard to the current state of equipment and personal protective equipment (PPE) at their hospital. If their facility was experiencing shortages, participants were asked to identify what was being done to address it. Additionally, participants were asked to identify whether all providers were given the same access to PPE or if certain departments (i.e., anesthesia or emergency medicine) had more access to PPE. Participants were then asked questions to categorize the level of COVID19 testing currently taking place at their hospital and to describe policy changes at the hospital including restructuring to the staffing model and/or if orthopaedic residents/fellows/attendings at their hospital were tasked with working on nonorthopaedic hospital floors.

Lastly, participants were asked open-ended, free-text questions to identify the most significant challenges to their orthopaedic practice in dealing with COVID-19. This included what they wish they had known prior to the outbreak that would have helped them now; how they are addressing the challenges being presented by COVID-19; and any personal experience, thoughts, or opinions as a medical professional working in the COVID-19 pandemic in their respective country.

\section{Analysis}

Statistical analysis was made using JMP Pro 15 by SAS. The data coding was done by a single person and provided by the investigators. Descriptive statistics were reported for continuous variables and percentages for categorical variables.

\section{Results}

The questionnaire was completed by 63 orthopaedic trauma surgeons representing 28 different countries and 14 US states 
a

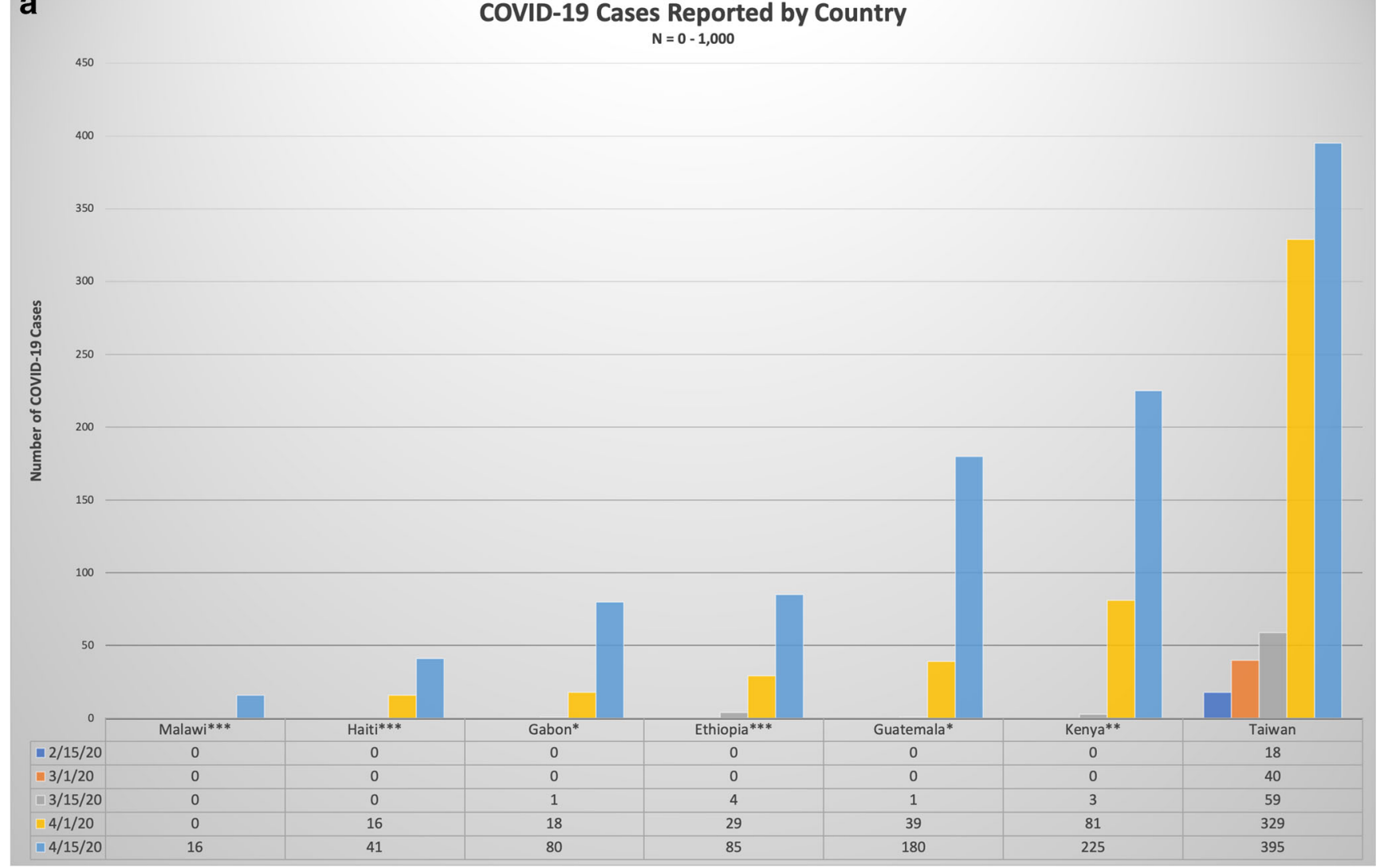

b

${ }_{14000} \quad$ COVID-19 Cases Reported by Country
COVID-19 Cases Reported by Country

$N=0-1,000$

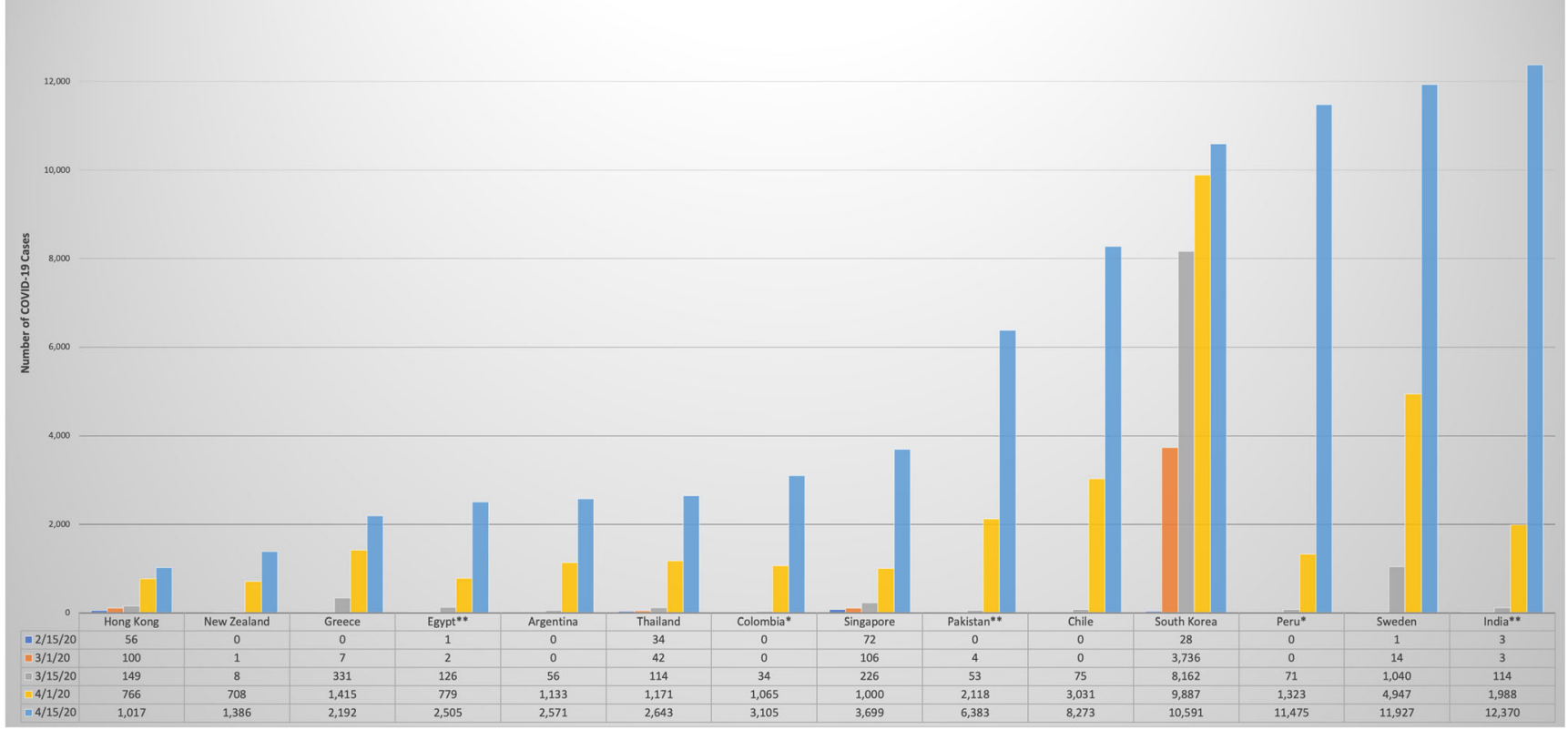

Fig. 2 a-c COVID-19 cases by country between February 15, 2020, and April 15, 2020 [11, 12]. Low-income country represented with ***. Lower middle-income country represented with **. Middle-income country represented with *

(Fig. 1). Of the surgeons who completed the survey, 19\% practice in a rural area with an average of five orthopaedic surgeons in their hospital system, while $81 \%$ of respondents practice in an urban setting with an average of 29 orthopaedic surgeons in their hospital system. Furthermore, three out of the 28 represented countries are classified as low-income countries, and eight are classified as lower-middle-income countries (39\% low- or middle-income countries) by the 


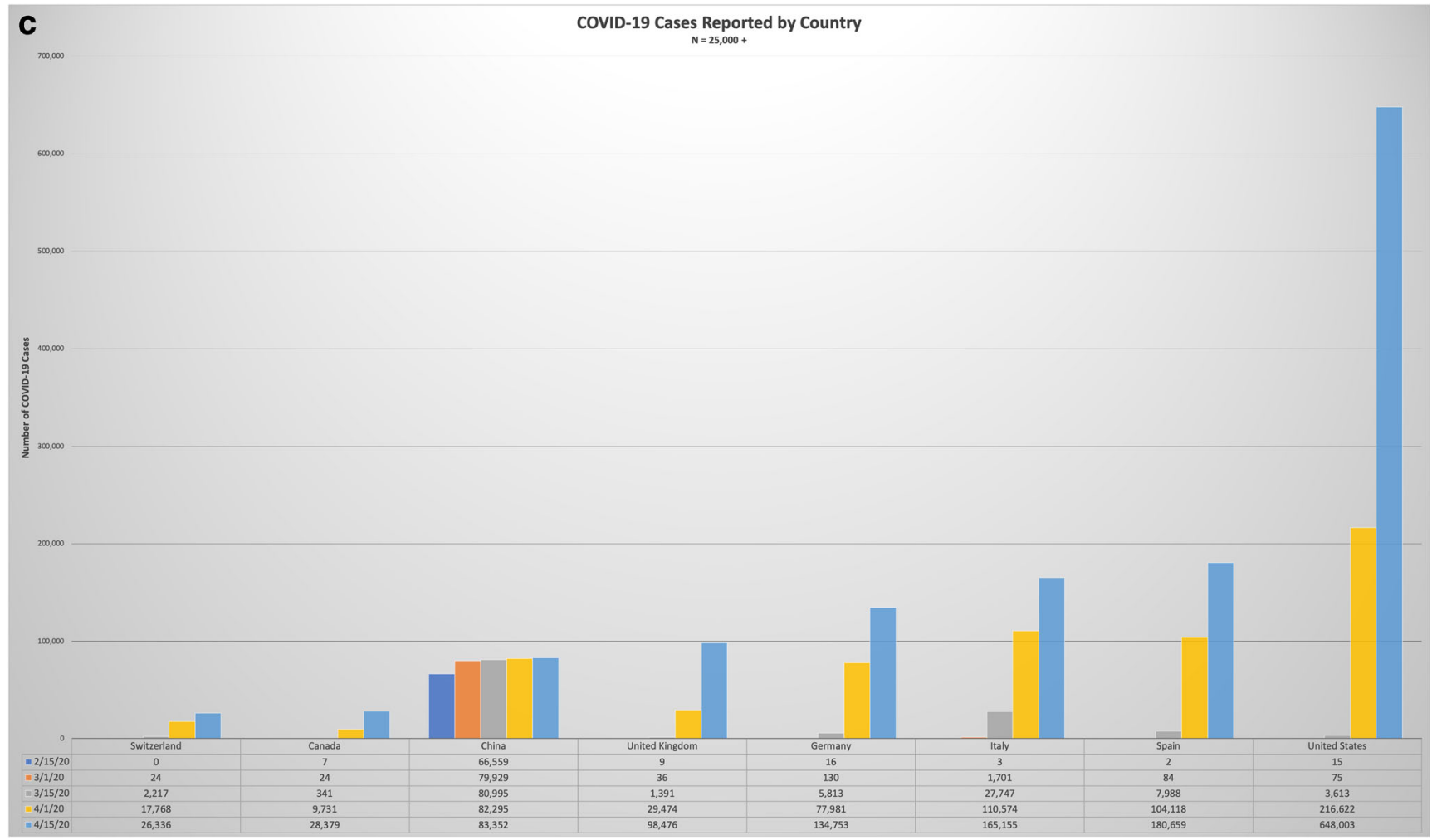

Fig. 2 (continued)

2019 WHO designation [13] (Table 1). Given the global and regional diversity represented by our sample pool, each participant provides a unique perspective in terms of when and to what extent COVID-19 affected their orthopaedic practice. As seen in Fig. 2-c, several participants began to experience COVID-19 in mid-February with cases continuing to climb through mid-April, while some participants have yet to experience a significant case load of COVID-19 patients.

While countrywide data is widely accessible in terms of total COVID-19 cases, it is difficult to glean specific regional and hospital ramifications of COVID-19 on a global scale. Consequently, each participant in the study was asked to identify the percentage of total patients in their intensive care unit (ICU) filled by COVID-19 (+) patients. Most respondents noted that their ICU was less than 50\% filled by COVID-19 positive patients, while only a few respondents noted $100 \%$

Table 2 Percentage of ICU occupied by COVID-19 (+) patients

\begin{tabular}{lll}
\hline Percentage & \# of Hospitals & \# of Total \\
\hline $100 \%$ & 3 & $4.84 \%$ \\
$76-99 \%$ & 5 & $8.06 \%$ \\
$51-75 \%$ & 7 & $11.29 \%$ \\
$<50 \%$ & 47 & $75.81 \%$ \\
\hline
\end{tabular}

The majority of respondents noted less than $50 \%$ capacity of their ICU beds by COVID-19 (+) patients. One respondent left this question unanswered capacity of their ICU by COVID-19 (+) patients (Table 2). In addition to differences in the number of COVID-19 patients in the ICU of hospitals across the world, the level of laboratory testing at each hospital varied dramatically where $83 \%$ reported testing of symptomatic patients only, $56 \%$ reported testing of surgical patients, $40 \%$ reported testing healthcare workers, and $10 \%$ reported no testing at all (Table 3 ).

The effects of COVID-19 are not only causing significant changes in the ICUs of each of the participating hospitals but greatly impacting orthopaedic trauma departments in terms of the number and type of orthopaedic procedures being performed. Of the respondents, $68 \%$ reported their hospital typically performs more than 40 orthopaedic procedures per week prior to COVID-19. However, now, just $5 \%$ of participating hospitals are performing more than 40 procedures per week, with $80 \%$ performing less than 20 procedures per week (Fig. 3). Additionally, the type of procedures being performed

Table 3 COVID-19 (+) laboratory testing by Hospital

\begin{tabular}{lll}
\hline Percentage & \# of Hospitals & \# of Total \\
\hline No testing & 6 & $9.52 \%$ \\
Symptomatic patients & 52 & $82.54 \%$ \\
Surgical patients & 35 & $55.56 \%$ \\
Healthcare workers & 25 & $39.68 \%$ \\
\hline
\end{tabular}

The majority of respondents noted testing of symptomatic patients for COVID-19. The specific type of COVID-19 test was not asked 


\section{Orthopaedic Procedures Performed Pre- and During COVID-19}

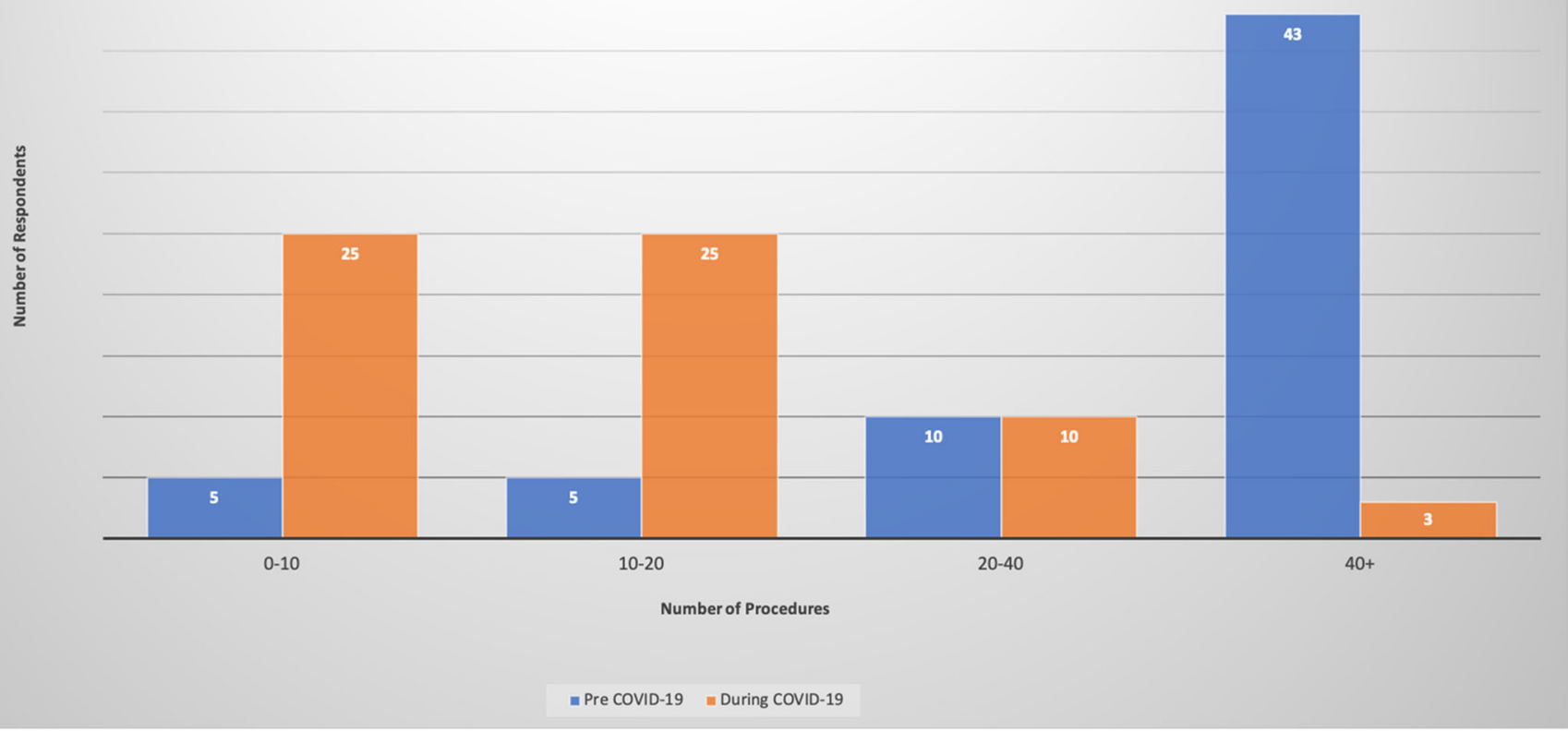

Fig. 3 Orthopaedic procedures performed prior to COVID-19 pandemic and during COVID-19 pandemic. Many orthopaedic departments who typically performed $40+$ surgeries per week are now performing less than 20 per week

has been affected with just $17 \%$ of participating hospitals currently performing elective orthopaedic surgery (Table 4 ).

In addition to the number and types of orthopaedic surgery being significantly altered during COVID-19, the actual type and mechanism of injury of patients itself are also different, as reported by $91 \%$ of participants (Table 5). When asked, "Have you observed differences in mechanism of injury trends in your practice since the onset of COVID-19?", $65 \%$ of participants answered yes, while $56 \%$ identified specific patterns of change in their patient pool. Their responses shed light on how the current crisis affects orthopaedic epidemiological trends across different geographical settings.

Orthopaedic departments themselves are also undergoing massive change during the COVID-19 pandemic. Of the respondents, $30 \%$ noted that their orthopaedic department has had to deploy orthopaedic residents, fellows, or attendings to work on non-orthopedic floors in order to help mitigate the overwhelming patient load. Furthermore, changes have been made to the department staffing models including rotating surgical teams with implemented isolation to minimize cross-exposure (56\%), reduction of personnel in operating rooms and on site to the minimum necessary to provide coverage, and lastly, the introduction of virtual meetings and case presentations via various video platforms (Table 6).

While orthopaedic departments are undergoing rapid change due to the COVID-19 pandemic, the departments and hospitals alike are experiencing significant shortages in equipment and/or personal protective equipment (PPE). Of the respondents, $85 \%$ noted some shortage of PPE, with the most common being N-95 masks (57\%), followed by surgical masks (44\%), face shields (41\%), and hand sanitizer (29\%). Many respondents' departments and hospitals were
Table 4 Types of surgeries performed during COVID-19 pandemic

\begin{tabular}{llr}
\hline Type of surgery & \# of Hospitals & \# of Total \\
\hline Emergency/trauma (e.g., compartment syndrome, open fracture) & 63 & $100.00 \%$ \\
Urgent trauma (e.g., femur fracture, hip fracture) & 62 & $98.41 \%$ \\
Sub-acute trauma (e.g., ankle fracture, humerus fracture) & 57 & $90.48 \%$ \\
Elective & 11 & $17.46 \%$ \\
\hline
\end{tabular}

Every respondent noted their hospital performing emergency/trauma surgeries, with only a small percentage still performing elective orthopedic surgery 
Table 5 Volume of orthopaedic injuries and changes in mechanism of injury during COVID-19

\begin{tabular}{lll}
\hline Volume of cases & \# of Hospitals & \# of Total \\
\hline Increased & 4 & $6.35 \%$ \\
Decreased & 57 & $90.48 \%$ \\
No change & 2 & $3.17 \%$ \\
Mechanism of injury & \# of Hospitals & \# of Total \\
Change & 41 & $65.08 \%$ \\
No change & 22 & $34.92 \%$ \\
\hline
\end{tabular}

The majority of respondents noted a decrease in total orthopedic volume, many of which noting a specific change in mechanism of injury as well

responding to these shortages through the reduction of allotted PPE per day (57\%), increased purchasing, and distribution from medical supply companies (51\%), as well as donations by community members/businesses (40\%). Additionally, the procurement of PPE within each hospital differed slightly in that at $58 \%$ of participating hospitals, intensivists/ anesthesiologists received PPE first, with 52\% of respondents noting equal distribution of PPE throughout all providers (Figs. 4, 5, and 6).

Table 6 Staffing changes during COVID-19

Fig. 4 Equipment and PPE shortages recorded by respondents. Most respondents $(86 \%)$ indicated a shortage in PPE or equipment, while only $14 \%$ indicated no shortages
Another remarkable change in orthopaedic departments across the world has been the adoption of telemedicine into their practice. Of the participating orthopaedic departments, $73 \%$ reported the adoption of telemedicine, with the majority implementing telephone and video visits (48\%) and some only telephone visits (25\%) (Fig. 7). Of the respondents representing high-income countries, $78 \%$ noted the adoption of telemedicine, while $55 \%$ of LMICs adopted telemedicine practices. Furthermore, 54\% of total respondents noted that telemedicine would most likely become a permanent change to their practice post COVID-19, with an even greater percentage $(74 \%)$ of those who have already implemented telemedicine practices in response to COVID-19 recognizing it would likely be a permanent change. Of those that identified telemedicine as a more permanent change to their practice, $80 \%$ represented HICs, and 20\% represented LMICs.

\section{Discussion}

This paper includes the largest sample size of orthopaedic trauma surgeons describing the effects of COVID-19 on their practice to date, which allows us to highlight the environment

\begin{tabular}{lll}
\hline Orthopaedic surgeons working on non-orthopedic floors & \# of Hospitals & \# of Total \\
\hline Yes & 19 & $30.16 \%$ \\
No & 44 & $69.84 \%$ \\
Changes to staffing model & \# of Hospitals & \# of Total \\
Rotating surgical teams with implemented isolation to minimize cross-exposure & 35 & $55.56 \%$ \\
No changes to organizational structure & 18 & $28.57 \%$ \\
Other & 10 & $15.87 \%$ \\
\hline
\end{tabular}

Many departments have implemented rotating surgical teams to minimize cross-exposure, and some orthopedic departments have had deployed surgeons to work on non-orthopedic floors

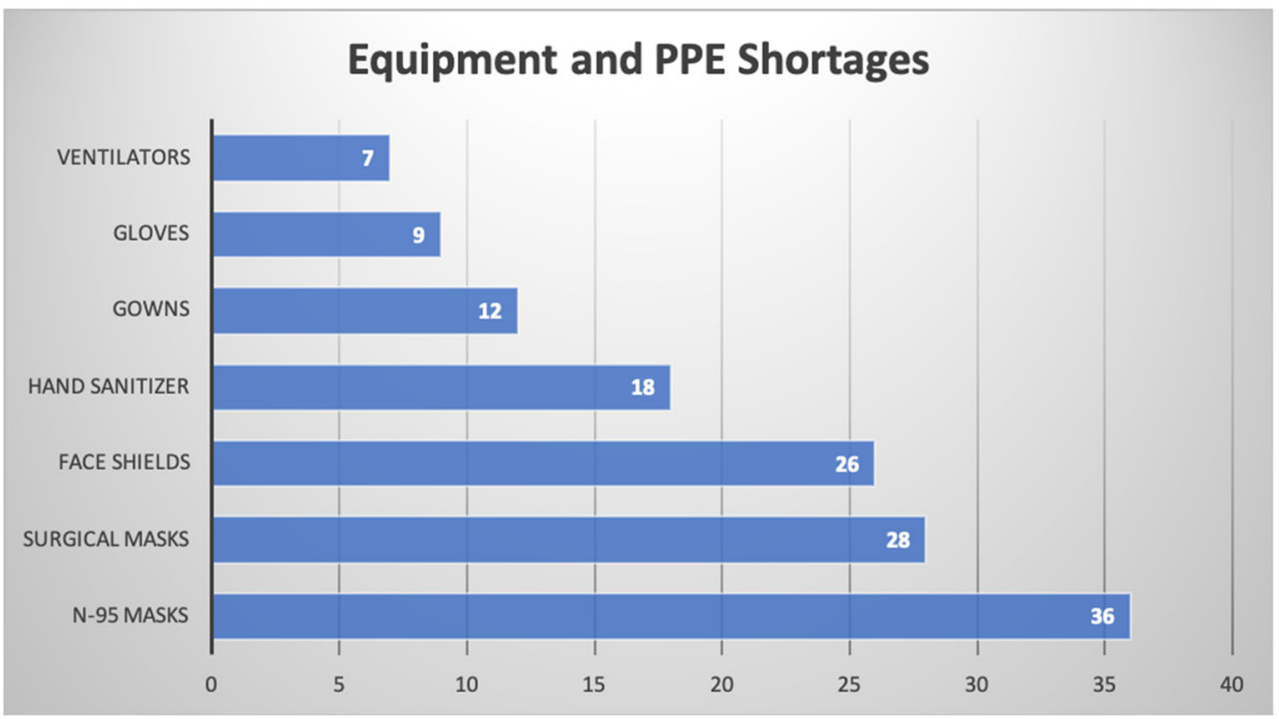




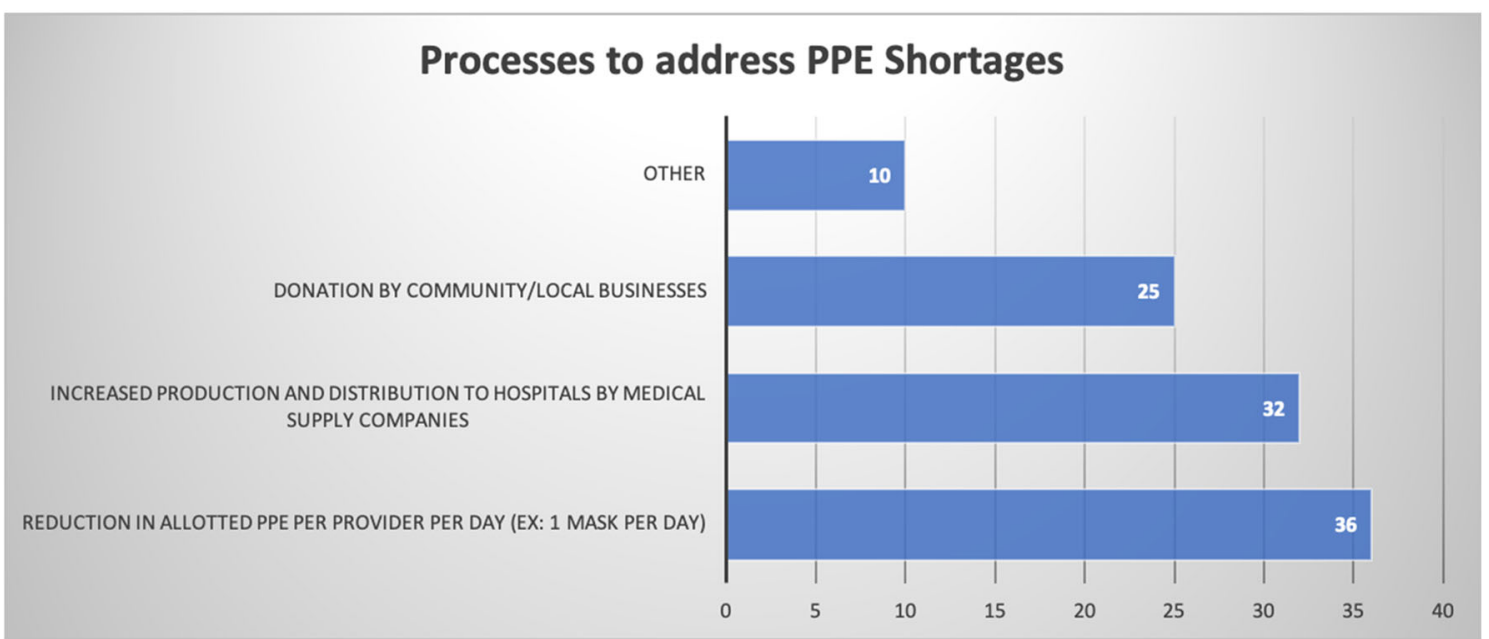

Fig. 5 Hospital mechanisms to address shortages in PPE. Many hospitals are relying on a reduction in PPE allotment, increased supply, and donations by community/local businesses in order to maintain adequate PPE levels

of orthopaedic trauma practices across the world currently combatting COVID-19. This survey includes the responses from 63 surgeons who represent 59 hospitals worldwide who themselves represent a total of 47,309 hospital beds and 1557 orthopaedic surgeons in their facilities (Table 1). While there are still many challenges to overcome, several lessons can be learned from the experiences presented by our study participants.

One of the main issues highlighted by emerging literature on COVID-19 is the shortage of equipment, specifically ventilators, as well as PPE, and what structural changes and policies have been implemented in order to help mitigate this. Many of our respondents echoed this concern, responding to the question, "What do you wish you would have known prior to this outbreak that would have helped alleviate challenges you are experiencing now?", with remarks related to PPE. Respondents noted their wish to know what the limit of PPE was at their facility prior to the pandemic, for the ability to stockpile PPE for their staff prior to the outbreak, and for better storage capacities of PPE in general as well as earlier policies to address the shortages. The results of this survey highlight that the shortages are not unique to one region or country but rather a global issue. Several strategies have worked well for our respondents, including donation of PPE by local community members and businesses as well as reduction in allotted PPE per provider per day. Additionally, prioritizing the types of providers at highest risk of exposure to the virus has allowed hospitals to maintain supplies at a level necessary to continue to function
Fig. 6 Method of allotment of PPE by specific hospitals. Many hospitals are allotting PPE to intensivists/anesthesiologists first, while some are providing equal PPE to all providers

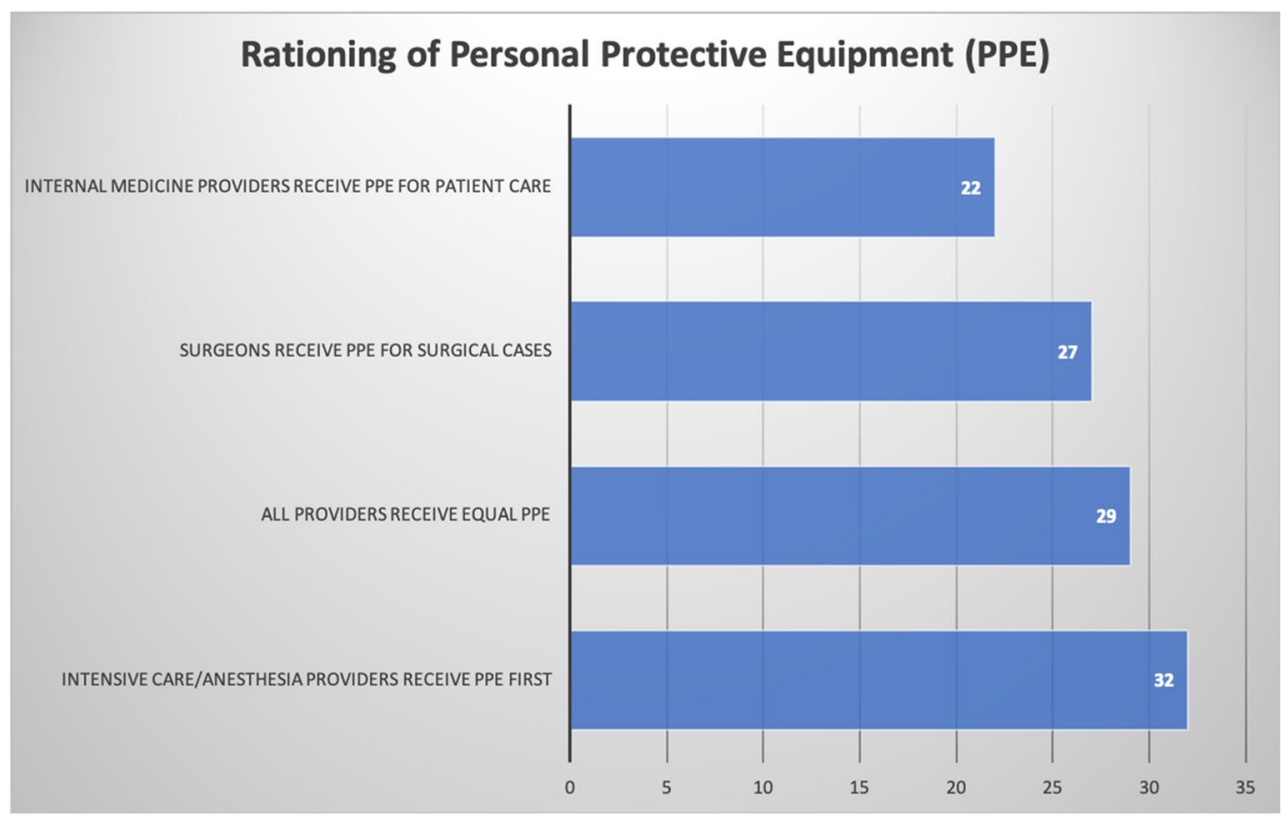




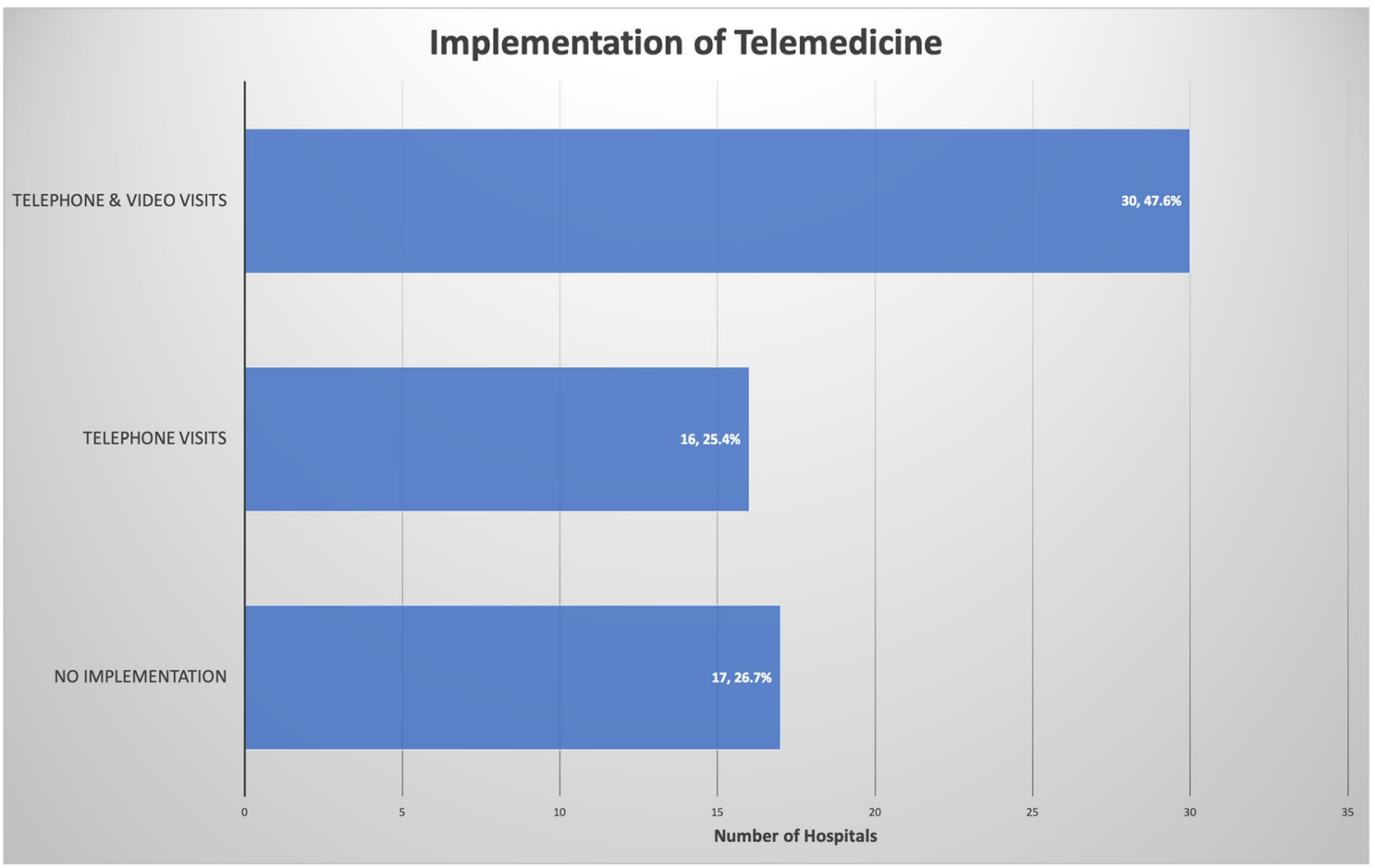

Fig. 7 Number of countries implementing telemedicine. Most countries are implementing telemedicine visits in the wake of the COVID-19 pandemic. Six out of 11 low- or middle-income countries (55\%) have implemented telemedicine, while 14 out of 18 high-income countries (78\%) have implemented telemedicine

\section{Limitations}

Our study has several limitations. First, our sampling technique was specific to academic surgeons who had attended professional meetings or formed professional relationships with our senior author. Our goal was to highlight the environment of orthopedic trauma practices around the world in combatting COVID-19 in an efficient and expedient manner, which is why this method was chosen. Second is a lack of knowledge as to specifics of what type of COVID-19 testing participants were referring to as well as what specific types of PPE referenced by respondents. Lastly, there is subjectivity in relying on surgeon's knowledge for percentage of ICU patients occupied by COVID-19 (+) patients and COVID testing data. However, these numbers were validated with official sources whenever the data was available.

\section{Conclusion}

To our knowledge, this is the largest data set characterizing the different COVID-19 situations and responses of orthopedic trauma practices around the world. There is much to be learned from each of these participants' responses. Furthermore, the distribution and completion of this questionnaire highlight the power of worldwide communication and coordination. In a short period of time, 63 orthopaedic trauma 
surgeons from 28 different countries were able to describe their unique challenges as it relates to their orthopaedic practice and hospital combatting the COVID-19 pandemic. It is important that we recognize the power of global communication and coordinated responses, learning from each other's successes and failures alike, in order to prevent a global pandemic like we are living through now from occurring again in the future.

\section{Compliance with ethical standards}

Conflict of interest On behalf of all authors, the corresponding author states that there is no conflict of interest for the submitted work. Unrelated to the submitted work, the following disclosures are reported by PA Cole: grants from DePuy Synthes and Stryker; grants from COTA, AONA, and OMeGA; grants from Stryker, Zimmer, Acumed, DePuy Synthes, and KLS Martin; personal fees from AO Foundation, Exactech and J\&J; other from BoneFoams Inc., outside the submitted work. LK Schroder also reports personal fees from Exactech and J\&J outside of the submitted work.

\section{References}

1. McKay B, Calfas J, Ansari T (2020) Coronavirus declared pandemic by World Health Organization. World Health Organization https://www.who.int/docs/default-source/coronaviruse/situationreports/20200311-sitrep-51-covid-19.pdf?sfvrsn=1ba62e57_10. Accessed 1 May 2020

2. Tharakan S, Gottron F, Lawrence S, Blyther T (2020) COVID-19: global implications and responses. Congressional Research Service https://crsreports.congress.gov/product/pdf/IF/IF11421. Accessed 1 May 2020

3. Ravelo J, Jerving S (2020) COVID-19 - a timeline of the coronavirus outbreak. DevEx https://www.devex.com/news/covid-19-atimeline-of-the-coronavirus-outbreak-96396. Accessed 1 May 2020

4. Haffajee R, Mello M (2020). Thinking globally, acting locally the U.S. response to Covid-19. New England journal of medicine. https://doi.org/10.1056/NEJMp2006740

5. Ranney M, Griffeth V, Jha A (2020) Critical supply shortages the need for ventilators and personal protective equipment during the Covid-19 pandemic. N Engl J Med. https://doi.org/10.1056/ NEJMp2006141

6. Fauci A, Lane H, Redfield R (2020) Covid-19 — navigating the uncharted. N Engl J Med. https://doi.org/10.1056/NEJMe2002387

7. Wu Y (2020) Survey of COVID-19 disease among orthopaedic surgeons in Wuhan, People's Republic of China. J Bone Joint Surg Am. https://doi.org/10.2106/JBJS.20.00417

8. Pinto R, Sousa R, Olivera A (2020) Preparing to perform trauma and orthopaedic surgery on patients with COVID-19. J Bone Joint Surg Am. https://doi.org/10.2106/JBJS.20.00454

9. Halawi M, Wang D, Hunt T (2020) What's important: weathering the COVID-19 crisis. J Bone Joint Surg Am. https://doi.org/10. 2106/JBJS.20.00419

10. Liang Z, Wang W, Murph D, Po Hui J (2020) Novel coronavirus and orthopaedic surgery: early experiences from Singapore. J Bone Joint Surg Am. https://doi.org/10.2106/JBJS.20.00236

11. Johns Hopkins University (2020). Johns Hopkins coronavirus tracker. Johns Hopkins Coronavirus Resource Center. https:// coronavirus.jhu.edu/map.html. Accessed 14 May 2020

12. Institute for Health Metrics and Evaluation (2020). IHME COVID19 Health Data. https://covid19.healthdata.org/united-states-ofamerica. Accessed 14 May 2020

13. World Bank Country and Lending Groups (2020). High, Low and Middle-Income Country Classification. https://datahelpdesk. worldbank.org/knowledgebase/articles/906519-world-bankcountry-and-lending-groups. Accessed 14 May 2020

14. Tanaka M, Oh L, Martin S, Berkson M (2020) Telemedicine in the era of COVID-19: the virtual orthopaedic examination. J Bone Joint Surg Am. https://doi.org/10.2106/JBJS.20.00609

15. Hollander JE, Carr BG (2020) Virtually perfect? Telemedicine for COVID-19. N Eng1 J Med. https://doi.org/10.1056/ NEJMp2003539

16. Keesara S, Jonas A, Schulman K (2020) COVID-19 and health care's digital revolution. N Engl J Med. https://doi.org/10.1056/ NEJMp2005835

17. Hollander JE, Sites F (2020) The transition from reimagining to recreating health care is now. N Engl J Med Catalyst

18. United States Congress (2020). The Telehealth Services During Certain Emergency Periods Act of 2020, United States Congress. https:/www.congress.gov/bill/116th-congress/house-bill/6074? $\mathrm{q}=\% 7 \mathrm{~B} \% 22 \mathrm{search} \% 22 \% 3 \mathrm{~A} \% 5 \mathrm{~B} \% 22 \mathrm{Telehealth}+$ Services+ During+Certain+Emergency+Periods+Act+of+2020\%22\%5D\% $7 \mathrm{D} \& \mathrm{~s}=1 \& \mathrm{r}=1$. Accessed 14 May 2020

Publisher's note Springer Nature remains neutral with regard to jurisdictional claims in published maps and institutional affiliations. 